\title{
R\&D modes and firm performance in high-tech companies: A research based on cross-boundary ambidexterity and network structures
}

\author{
Yushan Yang \\ School of Economics and \\ Management, Beijing University \\ of Posts and \\ Telecommunications \\ yangyushan233@163.com
}

\author{
Mengling Yan \\ School of Economics and \\ Management, Beijing University \\ of Posts and \\ Telecommunications \\ yanmengling@bupt.edu.cn
}

\author{
Xiaoying Dong \\ Guanghua School of \\ Management, Peking University \\ dongxy@gsm.pku.edu.cn
}

\author{
Yanni Hu \\ Policy and Economics Research \\ Institute, China Academy of \\ Information and \\ Communications Technology \\ yanni-aviva@foxmail.com
}

\begin{abstract}
This paper draws on the cross-boundary ambidexterity theory to propose that four different $R \& D$ modes impact firm performance differently and that cooperative network structure moderates the above relationships. The theoretical model is tested by using financial and patent data of 587 high-tech firms for 10 consecutive years in China. We find that different $R \& D$ modes have different impacts on a firm's financial and innovative performance, and network structure plays different moderating roles. Practically, this work guides high-tech enterprises to optimize their resource allocation, select the most appropriate $R \& D$ mode, and establish efficient cooperative networks.
\end{abstract}

\section{Introduction}

As an indispensable part of a firm's innovation strategy, appropriate R\&D modes have direct and various effects on a focal firm's performance (Boiko, 2021). In empirical studies, most scholars refer to internal R\&D and external R\&D as two major R\&D modes (Piga, 2004; Lokshin, Belderbos \& Carree, 2008; Narula, 2001)

It has been generally agreed that both $\mathrm{R} \& \mathrm{D}$ modes have a significant impact on firm performance. The internal R\&D mode enables firms to accumulate internal intellectual and technological capital, motivates firms to introduce advanced equipment, and improves their ability to digest and absorb new knowledge (Simonin, 1999), thus improving their innovation capacity and financial performance. The external R\&D mode, on the other hand, affects firm performance in three ways: resource complementation (Fritsch \& Franke, 2004), technological synergy (Okamuro, Kato \& Honjo, 2011), and knowledge spillover (D'Aspremont \&Jacquemin, 1988).

With the increasing attention to $\mathrm{R} \& \mathrm{D}$ modes, number of research streams underline the importance of open innovation which consists of external knowledge acquisition and external technology exploitation due to limited resources of firms when only adopt internal R\&D (Chesbrough, Vanhaverbeke \& West, 2006; Enkel, Gassmann \& Chesbrough, 2009; Huang \& Chou, 2013). Open innovation differentiates the way external resources are used. However, it does not differentiate the way internal knowledge is used.

In conclusion, extant typology of R\&D modes base either on organizational boundaries or technological boundaries. Few studies consider these two dimensions of R\&D activities as the same time. In fact, firms are frequently faced by two separate decisions: whether conduct R\&D activities along the organizational boundary and, whether conduct R\&D activities along the technological boundary. These two divisions are not mutually exclusive but orthogonal.

Cross-boundary ambidexterity refers to the ability that a firm pursues both explorative and exploitative innovation by leveraging both internal and external organizational resources (Russo \& Vurro, 2010). It suggests that R\&D modes can be divided both along the organizational boundary and the technological boundary, namely internal exploration, internal exploitation, external exploration, and external exploitation. It is easy to distinguish between the inside and outside of organizational boundary, i.e., whether the firm is collaborating with external partners. However, distinguishing technical boundary is relatively difficult. Both exploration and exploitation entail extensive firm learning activities and generate new knowledge. However, they differ in the way of learning. While exploration deviates a firm's old learning trajectory, exploitation follows or strengthens the old learning trajectory (Gupta et al., 2006). Under this categorization, four R\&D modes can be leveraged at the same time. Thus, the four $\mathrm{R} \& \mathrm{D}$ modes provide a comprehensive and intuitive description of a firms' R\&D strategies. 
Collaborative R\&D network forms when firms conduct R\&D activities with various partners. Different network positions have different impacts on firm performance (Gilsing V et al., 2008). Most studies have considered centrality and structural holes as two critical indicators of the essential attributes of network location. It is generally accepted that the higher the centrality of the network, the higher the firm's innovation performance. A study by Burt (1992) concluded that firms in structural hole locations have access to diverse and non-redundant heterogeneous information. Zaheer and Bell's study (2005) concluded that the number of structural holes occupied by a firm is positively related to the firm's innovation performance. However, as indicators of the number of alliance partners and the strength of relationships within an alliance network, centrality and structural holes fail to observe the process by which partner diversity affects the source of knowledge uptake, which in turn affects network efficiency and ultimately has an impact on firm performance. Moreover, there is no evidence on how the network situation effects the choice of R\&D modes. Existing research focuses on the single impact of $R \& D$ modes or network position on firm performance, but ignored that the fit between them may also work, thus cannot provide the optimal R\&D mode choice for firms in a specific network position.

To better understand the relationships between R\&D modes, firm performance, and partner diversity and help firms make a better R\&D decision, this study draws on the cross-boundary ambidexterity theory to classify four different $\mathrm{R} \& \mathrm{D}$ modes. It conducts an empirical study based on time-series panel data extracted from high-tech companies in China. This work focuses on the following two research questions:

1. How do different R\&D modes affect the financial performance and innovative performance of high-tech firms?

2. How does the collaborative network of firms affect the above relationships?

By answering the above questions, the finding of this study may guide high-tech firms to optimize resource allocation, choose the most appropriate $R \& D$ mode, and establish an efficient cooperative network.

\section{Literature review}

\subsection{R\&D modes and firm performance}

Early studies on R\&D modes mainly focuses on internal R\&D and external R\&D (Piga, 2004; Lokshin, Belderbos \& Carree, 2008; Narula, 2001). Internal R\&D refers to $R \& D$ activities in which firms independently use internal resources to accomplish $R \& D$ tasks. In contrast, external $R \& D$ refers to $R \& D$ activities in which firm cross organizational boundaries and cooperate with others to accomplish R\&D tasks with common resources (Faems, Bart \& Debackere, 2005). Later, as external $\mathrm{R} \& \mathrm{D}$ attracts more and more attention, scholars divide external R\&D into external knowledge acquisition and external knowledge exploitation along technology boundary (Chesbrough, Vanhaverbeke \& West, 2006; Enkel, Gassmann \& Chesbrough, 2009; Kuangpeng \& Christine, 2013).

Previous research on the relationship between R\&D modes and firm performance has yielded some insightful results. It is generally agreed that internal R\&D activities are beneficial to firm performance. However, conclusions on the impact of external R\&D on a firm's performance are inconsistent. Some scholars believe that collaboration is beneficial (Lundvall, 1993), while some scholars argue that collaboration has no effect or even negative effect (Berchicci, 2013).

In sum, existing studies describe R\&D modes at a coarse-grained level and fail to describe the actual R\&D behaviors of firms. The two mainstream divisions based on organizational and technical boundary respectively should be orthogonal. Secondly, extant studies tend to use a single assessment approach, i.e., the firm's financial performance or productivity performace, to measure the results of innovation activities (Dovev \& Miller, 2008; Ruihua, Tao \& Santoro, 2010; Mavroudi, Kesidou \& Pandza, 2020). However, results of innovative activities often reflect differently in both short and long term. Focusing only on the variation in firms' short-term financial data is inadequate to objectively measure them. Last but not least, current studies mainly use cross-sectional questionnaire data, lacking longitudinal studies with continuous tracking of the sample firms. Cross-sectional data is relatively weak to reveal the causal relationships between the focal variables (Rindfleisch et al., 2008) and questionnaire data is often criticized by subjectivity and potential common method bias.

\subsection{Cross-boundary ambidexterity theory}

Ambidexterity is the ability of organizations to simultaneously engage in exploratory and exploitative innovation (Tushman \& O'Reilly III, 1996). Exploratory innovation refers to activities that increase variation by deviating from the old learning track of technology. Representative activities include product search, trial and error, experimentation, and discover to find new technology areas and opportunities that contribute to long-term growth despite high failure rates and uncertainty. Exploitative innovation refers to activities that decrease variation by optimizing, selecting, and implementing technologies or products along original learning track. Although exploitative activities serve to 
improve the productivity of existing technologies and reduce operating costs, they are usually limited in improving long-term viability (Gupta et al., 2006).

Cross-boundary ambidexterity refers to firms' ability to balance exploration and exploitation across organizational boundaries. It suggests that R\&D modes can be divided along both the organizational boundary and the technological boundary. Four distinct R\&D modes can be resulted, namely internal exploration, internal exploitation, external exploration, and external exploitation. Under this categorization, four R\&D modes can be leveraged at the same time. Thus, the four R\&D modes provide a comprehensive and intuitive description of firms' R\&D strategies.

Exploitation relates to firm's current viability (March, 1991). When firms conduct exploitation activities, many of the expenditures have a significant fixed-cost component, which suggest exploitation can offer some possible fixed-cost relief. At the same time, unlike external innovation activities, using resources within firms is more economic (Laursen \& Salter, 2006). Since the cost of innovation decreases and the efficiency of business activities increases along the learning curve through the further diffusion and application of technologies already available within the organization (Linton \& Walsh, 2004), financial performance is suggested to be improved steadily. From a long-term perspective, developing technology internally meets the needs of capability building for a firm (Tsai \& Wang, 2008), as a result, firms are more likely to produce higher qualified innovation products and achieves incremental innovation optimization of products and services (Fishcher et al, 2010), which reflects on firm's innovation output performance. Thus, we propose:

Hypothesis la: Internal exploitation has a positive impact on firm's financial performance.

Hypothesis 2a: Internal exploitation has a positive impact on firms' innovation performance

When a focal firm conducts internal exploration activity, exploration attribution means it may critically influence a firm's future viability (March, 1991), thereby has a more significant impact on long-term performance. Technology endogeny and internal access to resources are two main characteristics of internal exploration. It requires firm's core technology to be acquired by itself, which helps the firm greatly enhance its innovation capability and improve the efficiency of innovation output (Hamel, 1991). Also, new products and services generated through internal exploratory activities have non-substitutability, which helps firm gain a larger market share and positively affect the financial performance in the short term. In addition, competitive advantage with barriers generates innovation value.
Hypothesis $1 b$ : Internal exploration has a positive impact on firm's financial performance.

Hypothesis $2 b$ : Internal exploration has a positive impact on firms' innovation performance

Complementary resource of partners is a crucial factor of external innovation activities. As the difficulty and depth of technological breakthroughs in various fields are increasing, it is vital for firms to complement each other. Complementary resources from partners help companies achieve complementary strengths, rapidly acquire technologies and markets. R\&D alliances are considered to have long lasting effect on firms (Teece, 1980), as a result, external exploitation is suggested to have a positive effect on firm's long term innovation performance. Also, exploitation attribution benefits firms on short term financial performance since it is less cost than exploration in terms of both fixed costs and the expected rate of success (Lampert \& Kim, 2019).

Hypothesis 1c: External exploitation has a positive impact on firm's financial performance.

Hypothesis 2c: External exploitation has a positive impact on firms' innovation performance

R\&D cooperation is mostly the domain of firms pursuing radical innovations rather than incremental innovations (Tether, 2002). Focus on long term performance, external exploration activities that cross organizational and technological boundaries help firms achieve significant breakthroughs, benefit the quality of invention. At the same time, when firms conduct external exploration, partners are acute to management issues such as inefficiencies and information asymmetries in the operation of firms due to their close business relationships during R\&D innovation (MoraValentin, Montoro-Sanchez \& Guerras-Martin, 2004). Although exploration entails unknown outcomes and risk, cooperation could significantly reduce the cost and the knowledge gained from exploration efforts is being effectively exchanged and integrated within the firm, resulting in better financial performance (Lampert \& Kim, 2019).

Hypothesis 1d: External exploration has a positive impact on firm's financial performance.

Hypothesis 2d: External exploration has a positive impact on firms' innovation performance

\subsection{Network structure efficiency}

Networks are naturally formed in collaborative $\mathrm{R} \& \mathrm{D}$. The access to resources varies depending on the firm's network position. It is generally believed that firms with central network position are more likely to get better innovation performance. Superior network position helps firms integrate diversified exogenous resources in a timely manner, through which firms 
acquire stronger R\&D capabilities and achieve higher status in the industry.

Existing literature measures the firm's situation in the collaborative network mainly in terms of network centrality and structural holes (Powell, Koput \& SmithDoerr, 1996), based on the number of partners and the tightness between partners (Ibarra, 1993). In this work, we incorporate the heterogeneity of partners' knowledge to establish a new variable to measure firm's network position. We start by measuring the network efficiency based on proportion (Herfindahl-Hirschman Index) of relevance of a partner.

$$
N S E_{t}=\frac{1-\sum_{i, m}\left(P P_{i m}\right)^{2}}{\text { The total frequency }}
$$

Where $\mathrm{m}$ is the type of cooperative partners, $\mathrm{PP}$ is a proportion of frequency at year $t$ for one or more of reported categories: (1) universities and research institutions; (2) firms; (3) individuals; (4) government agencies; (5) other institutions. The total frequency refers to the total frequency of cooperation between the firm and all 5 types collaborators.

NSE is greater when a firm has more types of partners and less reliance on a particular type of partner.

Exploratory innovation requires a great number of R\&D investment, and it leads to resource depletion if a firm fails to control its investment (Levinthal \& March, 1993). In particular, SMEs have limited resources to afford high R\&D expenses. Over-allocating resources to exploratory innovation will harm their financial performance. In this case, NSE alleviates the pressure on resources by providing a balanced and diversified source of knowledge, whether for internal exploration or external exploration activities. In addition, firms with efficient network structures have the advantage of controlling information and interest channels (Burt, 1992), reducing costs and strengthening the growth of short-term financial performance.

Hypothesis 3a: NSE enhances the positive effect of internal exploration on financial performance.

Hypothesis 3b: NSE enhances the positive effect of external exploration on financial performance.

Overly exploitative innovation may lead to experience path dependence and failure to react to environmental changes, undermining the value it brought (Andriopoulos \& Lewis, 2009). In this case, an efficient network position helps to improve the accuracy and timeliness of information exchange between firms, identify potential changes in the market, and reduce innovation risk (Lahiri \& Naraynan, 2013). Also, when linkages are created with unrelated partners, an efficient network structure creates more opportunities to identify market gaps (Ahuja, Jr \& Mitchell, 2009). Benefits from exploitation innovation are further magnified to a large extent when a firm acts as an intermediary between two unrelated organizations (Uzzi, 1997). Therefore, innovation performance brought by exploitation activities of firms with high NSE can be enhanced.

Hypothesis 4a: NSE enhances the positive effect of internal exploitation on innovation performance.

Hypothesis 4b: NSE enhances the positive effect of external exploitation on innovation performance.

The hypothetical model of our research is shown in Figure 1. In summary, the main idea of the model is that any of the four R\&D modes will positively affect both short-term financial performance and long-term innovation performance. In particular, as NSE can alleviate resource depletion in exploration activities and path dependence in exploitation activities, we suppose that NSE enhances the positive impact of two exploratory modes on financial performance and two exploitative modes on innovation performance.

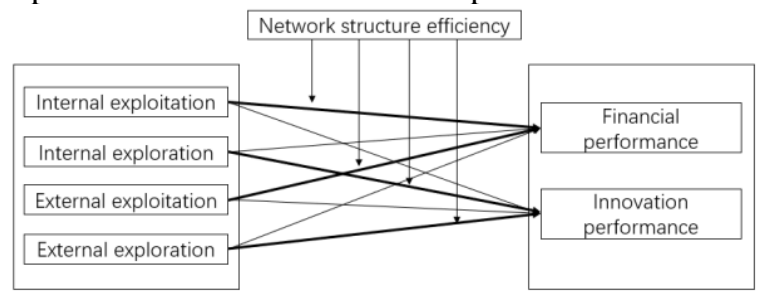

Figure 1. Research model

\section{Research method}

\subsection{Data source}

To study the relationships between R\&D modes and firm performance, our research obtains and selects panel data during 2008-2017 of 587 A-share firms with high-tech enterprise certification in China from Wind database and China National Intellectual Property Administration. We extract 5870 financial data and 454,000 patent data in total, among which financial data includes indicators such as the total number of firm employees, total operating income, return on net assets, and R\&D expenses. Patent data includes indicators, such as patent classification numbers and applicant information.

\subsection{Model construction}

The following econometric model is developed in our work based on theoretical analysis in section 2 .

Perform $_{x t}=\beta_{0}+\beta_{1} R \& D+\beta$ Control $_{x t}+f+\varepsilon_{x t}$

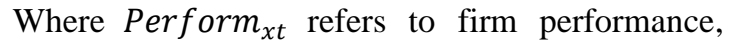
$R \& D$ refers to four R\&D modes, Control $_{x t}$ refers to the control variables, $f$ refers to fixed effects variables include the industry, listed board, and ownership, $\varepsilon_{x t}$ refers to random error term.

Further, considering the lagging impact of R\&D, the moderating effect of NSE, four different R\&D 
modes and examining firm performance by observing financial performance and innovation performance, we updated the model as shown below.

FinaPerf $f_{x(t+2)}=\beta_{0}+\beta_{11} R \& D_{11}+\beta_{12} R \& D_{12}+\beta_{13} R \& D_{13}+\beta_{14} R \& D_{14}+$

$\beta_{2}$ Regu $+\beta_{3}$ Inte $+\beta$ Control $_{x t}+f+\varepsilon_{x t}$

InovPerf $x_{x(t+2)}=\beta_{0}+\beta_{11} R \& D_{11}+\beta_{12} R \& D_{12}+\beta_{13} R \& D_{13}+\beta_{14} R \& D_{14}+$

$\beta_{2}$ Regu $+\beta_{3}$ Inte $+\beta$ Control $_{x t}+f+\varepsilon_{x t} \quad$ (4)

Where $F$ inaPerf $f_{x(t+2)}$ refers to the firm's financial performance with a two-year lag, $\operatorname{InovP\operatorname {er}} f_{x(t+2)}$ refers to firm's innovation performance with a two-year lag, $R \& D_{11}, R \& D_{12}, R \& D_{13}, R \& D_{14}$ refers to the four different $\mathrm{R} \& \mathrm{D}$ modes respectively, Regu refers to the moderating variable NSE, and Inte refers to the interaction term variable between moderating variable and the R\&D modes.

\subsection{Variable treatment}

\section{Independent variables}

Previous research mainly uses marketing and accounting indicators to measure a firm's financial performance (Gentry \& Shen, 2010). In view of the fact that innovation activities have a lag effect (Powell, Koput \& Smith-Doerr, 1996), we draw total operating income with a lag of two years to present financial performance. Also, we following Hagedoorn (2003) to draw a two-year lag of number of granted invention patents to measure firm's innovation performance.

2. Dependent variables

According to cross-boundary ambidexterity, this work suggests that R\&D modes can be divided along the organizational boundary and the technological boundary, resulting in four types of $\mathrm{R} \& \mathrm{D}$ modes, namely internal exploration, internal exploitation, external exploration, and external exploitation. A patent belonging to both internal innovation and exploitation innovation is an internal exploitation patent, and the same applies to other patents. Internal and external innovation are identified by the presence of partners outside the organizational boundary according to patent applicant information (Karamano, 2016). An invention patent is counted as an internal innovation only when a firm is the sole applicant of the patent. If one patent has more than 1 applicants, it is identified as an external innovation. To decide whether a firm conducted exploratory innovation or exploitative innovation in a specific year, we follow previous work to use the main classification numbers of its patents in previous years (Gilsing, 2008; Wang et al., 2014). To be more specific, a patent is classified as exploratory innovation when the first four codes of its main classification number of patents have not yet appeared in previous years. Otherwise, it is classified as exploitative innovation. Then exploratory or exploitative innovation is measured by the number of exploratory or exploitative patents that a firm achieved in a certain year. Internal-external and exploitation-exploration are pairwise combined to form four R\&D modes. For example, internal exploitation refers to the patent for which the applicant is the sole proprietor, and the first four places of patent classification number have appeared in the past.

3. Moderating variable

We construct a network structure efficiency variable to reflect the diversity and heterogeneity of network resources based on the Herfindahl index and the research method of Patel et al. (Patel et al., 2014). NSE is calculated as follows. First, we determine the classification of patent applications and divide it into 5 types based on the heterogeneity of the resources they provided. Second, weight of each type of partners is determined by collaboration frequency represented by patent numbers. Third, calculate network structure efficiency according to formula (1).

4. Control variables.

In sum, 8 variables are selected as control variables according to previous related work. More specific, the control variables include firm size, measured by total number of employees (Becker-Blease et al.), R\&D expenses (Wilson, 1977), management expenses (Gee, 1972), development ability, measured by growth rate of ROA (Begley, 1995), and knowledge accumulation, measured by the accumulation of granted patents before the observation year (Kuo, Wu \& Lin, 2019). Besides, since industries, ownership, and firm listing information (whether the firm is listed in the main board) keep constant each year, they are included and fixed in regression model. Table 1 describes the industry distribution of the 587 firms

\section{Table 1. Industry distribution of the 587 firms}

\begin{tabular}{lcc}
\hline \multicolumn{1}{c}{ Industry } & Freq. & Percent \\
\hline 1 Manufacturing & 272 & 46.34 \\
2 Information transmission, Software and Information Technology & 94 & 16.01 \\
Services & 40 & 6.81 \\
3 Construction & 34 & 5.79 \\
4 Real Estate & 30 & 5.11 \\
5 Wholesale and Retail Trade & 22 & 3.75 \\
6 Leasing and Business Services & 20 & 3.41 \\
7 Finance & 14 & 2.39 \\
8 Electricity, heat, gas and water production and supply & 13 & 2.21 \\
9 Mining & 12 & 2.04 \\
10 Scientific Research and Technology Services & 11 & 1.87 \\
11 Transportation, storage and postal services & 9 & 1.53 \\
12 Culture, Sports and Entertainment & 6 & 1.02 \\
13 Water, Environment and Public Facilities Management & 3 & 0.51 \\
14 Accommodation and Food Services & 3 & 0.51 \\
15 Comprehensive & 2 & 0.34 \\
16 Agriculture, forestry, animal husbandry and fishing & 1 & 0.17 \\
17 Residential services, repairs and other services & 1 & 0.17 \\
18 Education & &
\end{tabular}

In this study, data analysis excluded samples with missing financial data indicators and invalid patent legal status, including "active abandonment of patent rights", "invalidation of patent rights" and so on. All variables are logarithmically processed to obtain a normal distribution to satisfy the assumptions of the econometric model. The descriptive statistics of 
variables were analyzed by Stata 16 , and results are shown in Table 2.

\section{Table 2. Descriptive statistics of variables}

\begin{tabular}{lccccc}
\hline \multicolumn{1}{c}{ Variables } & $\mathrm{N}$ & mean & $\mathrm{sd}$ & $\min$ & $\max$ \\
\hline 1 Financial performance & 4470 & 21.23 & 1.899 & 13.54 & 28.69 \\
2 Innovation performance & 4696 & 2.091 & 1.887 & 0 & 9.009 \\
3 Firm size & 5123 & 7.463 & 1.725 & 1.792 & 13.22 \\
4 R\&D expenses & 3968 & 17.53 & 1.590 & 7.601 & 23.68 \\
5 Management expenses & 5226 & 18.46 & 1.355 & 14.23 & 25.80 \\
6 Development ability & 3884 & -0.0630 & 0.814 & -6.172 & 7.812 \\
7 knowledge accumulation & 5870 & 2.259 & 2.435 & 0 & 10.78 \\
8 Internal exploitation & 5870 & 1.742 & 1.790 & 0 & 9.007 \\
9 Internal exploration & 5870 & 0.182 & 0.512 & 0 & 5.561 \\
10 External exploitation & 5870 & 0.536 & 1.238 & 0 & 8.739 \\
11 External exploration & 5870 & 0.0510 & 0.288 & 0 & 4.779 \\
12 NSE & 5870 & 0.00100 & 0.0100 & 0 & 0.223 \\
13 Firm age & 5870 & 2.50777 & 0.5841 & 0 & 4.205 \\
\hline
\end{tabular}

\section{Research Results}

The panel data of 587 A-share high-tech listed companies in China from 2008-2017 were subjected to Hausman test, which supported the fixed effects model, and the regression results are shown in Table 3 .

\section{Table 3. Regression result}

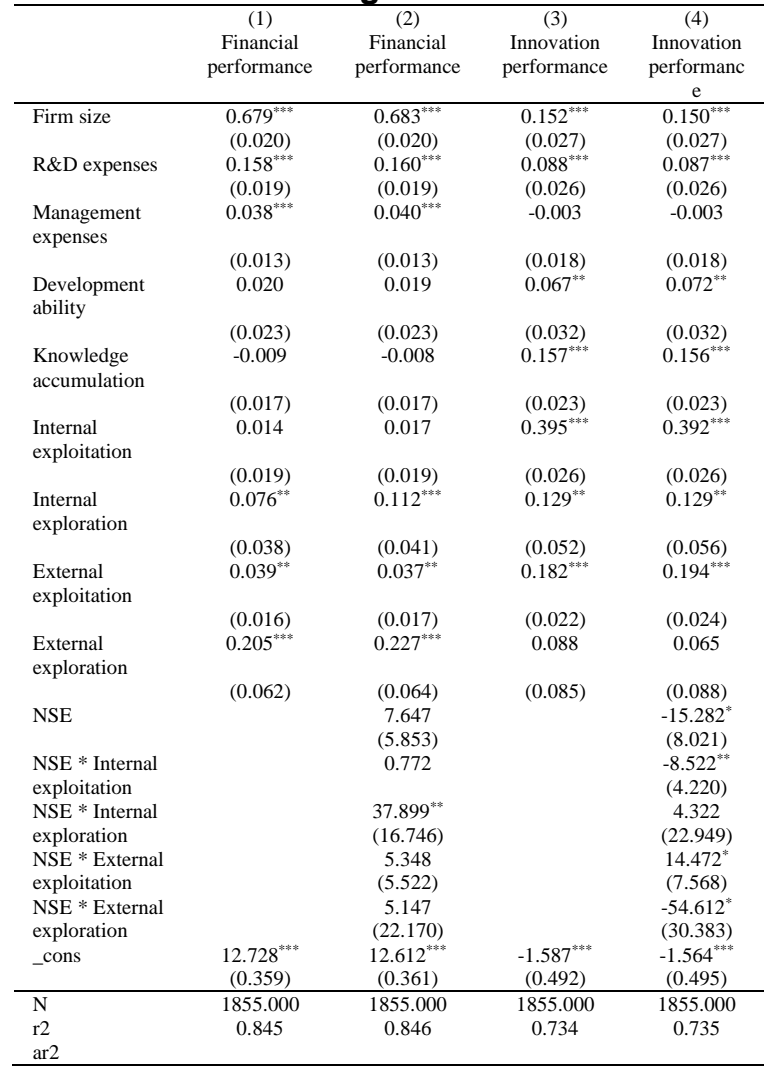

Regression results of Model (1) represent that internal exploration $\left(\beta_{12}=0.076, \mathrm{p}<0.050\right)$, external exploitation $\left(\beta_{13}=0.039, \mathrm{p}<0.050\right)$ and external exploration $\left(\beta_{14}=0.205, \mathrm{p}<0.001\right)$ all have a significant positive effect on financial performance. Hypotheses $\mathrm{H} 1 \mathrm{~b}, \mathrm{H} 1 \mathrm{c}$, and $\mathrm{H} 1 \mathrm{~d}$ are supported, while hypothesis H1a was not supported.
Regression results of Model (2) represent that only the mediate effect of NSE on the impact of internal exploration on financial performance is significant with coefficient $=37.899(\mathrm{p}<0.050)$. Interaction effects are plotted in Figures 2 for visual illustration.

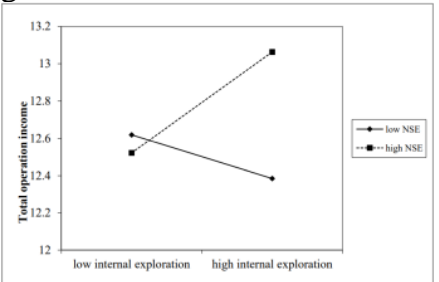

Figure 2. NSE * Internal exploration

The result shows that the effect of internal exploration on operating income is negative when NSE is low, while it becomes positive and the slope increases with NSE rises, indicating that NSE plays a significant positive moderating role in the process. Hypothesis $\mathrm{H} 3 \mathrm{a}$ is supported, and hypothesis H3b is not supported.

Regression results of Model (3) indicate that internal exploitation $\left(\beta_{11}=0.395, \mathrm{p}<0.001\right)$, internal exploration $\left(\beta_{12}=0.129, \mathrm{p}<0.050\right)$, and external exploitation $\left(\beta_{13}=0.182, \mathrm{p}<0.001\right)$ all have a significant positive effect on financial performance. Hypotheses $\mathrm{H} 2 \mathrm{a}, \mathrm{H} 2 \mathrm{~b}$, and $\mathrm{H} 2 \mathrm{c}$ are supported, while hypothesis $\mathrm{H} 2 \mathrm{~d}$ is not supported.

Regression results of Model (4) represent that the mediate effect of NSE on the impact of Internal exploitation and external exploitation on innovation performance are both significant. For Internal exploitation, the effect is negative with coefficient $=8.522(\mathrm{p}<0.1)$ while that is positive for external exploitation with coefficient $=14.472(\mathrm{p}<0.1)$ Interaction effects are plotted in Figures 3 and Figure 4 for visual illustration.

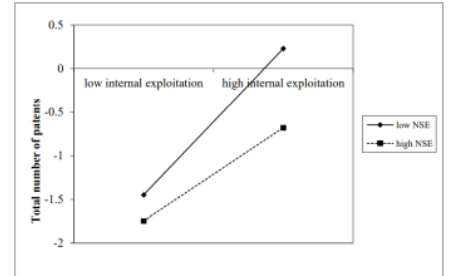

Figure 3. NSE * Internal exploitation

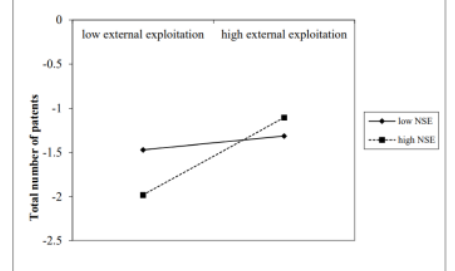

Figure 4. NSE * External exploitation

Results show that the effect of internal exploitation on the number of patents is positive when NSE is low, and it remains positive while the slope decreases with 
NSE rises, indicating that NSE plays a significant negative moderating role in the process. Hypothesis $\mathrm{H} 4 \mathrm{a}$ is not supported. The effect of external exploitation on the number of patents is positive when NSE is low, and it remains positive and the slope increases with NSE rises, indicating that NSE plays a significant positive moderating role in the process. Hypothesis $\mathrm{H} 4 \mathrm{~b}$ is supported.

\section{Discussion and conclusion}

To reveal the relationship between $\mathrm{R} \& \mathrm{D}$ modes and firm performance and the moderating role of network structure, we conduct an empirical study based on the panel data of 587 Chinese high-tech firms from 2008-2017. We conclude that internal exploration, external exploitation, and external exploration have significant positive effects on firms' short-term financial performance. NSE significantly enhances the positive effect of internal exploration on financial performance. Internal exploitation, internal exploration, and external exploitation have significant positive effects on firms' long-term innovation performance. NSE significantly enhances the positive effect of external exploitation on firms' innovation while significantly weakens the positive effect of internal exploitation on firms' innovation performance.

\subsection{Discussion}

Our findings indicate support for the notion that internal exploration and external exploitation have a significant positive effect on both financial and innovation performance, which is consistent with the findings of Russo \& Vurro (2010)'s research on 153 global fuel firms during the period of 1999-2006. Also, the significant positive effect of external exploration on financial performance complement Tsai \& Wang's (2008) study of Taiwanese manufacturing firms by new financial indicator, while the positive effect of internal exploitation on innovation performance refines the findings of Bruno \& Veugelers (2006) by reclassifying the internal R\&D.

Contrary to the hypothesis, the effect of internal exploitation on financial performance and the effect of external exploration on innovation performance were not significant. To begin with, firms conducting the external exploration may develop path dependency and reduce genuine new knowledge learning (Ahuja \& Lampert, 2001). Then, frequent external exploration may lead to the distraction of management and the exponential increase in integration costs (Moilanen, Østbye and Woll, 2014). Next, when firms wish to bring about performance growth through external exploration, specific playing conditions are required (Wilden et al.,
2013). Also, innovation performance may need to be observed in a more extended period to examine. The factors all above could lead to a non-significant positive effect of external exploration on firms' innovation performance.

In addition to the main effects, our results also suggest that network structure efficiency plays an important moderating role between $R \& D$ modes and firm performance.

On the one hand, NSE enhances both the positive effect of internal exploration on financial performance and the positive effect of the external exploitation on innovation performance. In other words, when a firm adopts the R\&D strategy of "internal exploration + external exploitation", NSE can magnify the complementary effect, which reflects in both short- and long-term firm performance. Kauppila (2010) has revealed that intra- and inter-organizational approaches are not substitutions but complementary relationships, and the findings of our research further illustrate which network situations could maximize the advantages of firms that balance internal and external resources and ambidexterity innovation.

This interpretation of our results is strengthened by the findings presented in an article pertaining to firms' resources and sustained competitive advantages (Barney, 1991). It found that there are two different patterns of ways for firms to absorb external knowledge. One case is that external sources provide knowledge exclusively to firms through R\&D collaborations. In that case, external knowledge becomes a valuable resource through its diversity and exclusivity as no one else has access to the particular technology. Exclusivity decreases whenever a firm decides to acquire external knowledge from an additional source (Parker \& Alstyne, 2005). Firms with high NSE acquire knowledge of both diversity and exclusivity, and get better performance when they use external exploitation to capture innovation performance.

Another case is when multiple external sources provide knowledge inputs to a wide range of firms, only those who can combine and redeploy the diffused external knowledge in a unique way may ultimately benefit from acquiring knowledge. Firms with high NSE are constantly receiving diverse knowledge from the network. Cohen and Levinthal (1990) argue that absorptive capacity depends on the processes within the organization that enable the organization to share, exchange, and transfer individual-level learning to the organizational level and is therefore path-dependent and cumulative in nature. As firms practice acquiring and transforming diverse knowledge multiple times in collaborative networks, the growth of absorbing capacity contributes to the greater speed, frequency, and scale of innovation, facilitating the firm's ability to 
transfer realizations of knowledge when it conducts its own exploratory innovation activities. Therefore, NSE enhances the positive impact of internal exploration on financial performance.

On the other hand, NSE weakens the positive impact of internal exploitation on firms' innovation performance. Firms in a balanced network have to devote significant resources to monitoring and managing incoming knowledge flows (Moilanen, Østbye \& Woll, 2014). The more diverse the sources of external knowledge are, the more the firm is obliged to correspondingly increase the resources devoted to managing incoming knowledge, thus reducing resources devoted to internal knowledge generation processes. Firms' investment in diverse external knowledge sources increases search, coordination, detection, and transaction costs at the expense of internal innovation efforts, which may ultimately lead to a loss of innovation value from internal exploitation activities. It was found that when firms overfocus on the acquisition of external knowledge resources, intentions of investing in their own R\&D activities are weakened to some extent (Yu, Yuan \& Li, 2019), which in turn prompts firms to form a large amount of non-absorption redundancy, increasing cost of business development and new knowledge creation. Finally, innovation value brought by internal exploitation innovation goes away.

Last but not least, network structure efficiency appears to offer no significant regulating effect in the process of external exploration on financial performance. Hoang and Rothaermel (2010) pointed out that exploration alliances typically involve the development of new knowledge that is characterized by tacit and uncertain value. Only if new knowledge is integrated into broader organizational capabilities, it can be utilized for critical tasks and gain strategic value. In contrast to external exploitation, external exploratory focus firms to new, cutting-edge knowledge, which in turn, correspondingly, presents the challenge of learning and integrating the knowledge of partners. Difficulties arise when there are diversified partners with different dominant logic and organizational structure (Lane \& Lubatkin, 1998). Although firms with high NSE are exposed to extensive knowledge which contributes to greater innovation output, financial performance may not be significantly affected as the rising difficulty in integration and management.

\subsection{Conclusion}

This study provides three theoretical implications. Firstly, we propose a new typology of R\&D modes. While previous work distinguishes R\&D modes only along the organizational boundary or only along the technological boundary, this work combines these two boundaries based on crossboundary ambidexterity theory and derive four different R\&D modes. Secondly, we construct an indicator based on Herfindahl index to measure the equilibrium of the collaborative network in which the firm locates. We find that NSE has a significant moderating effect on the relationship between a firm's R\&D modes and its performance and reveals the reasons. Thirdly, the findings of this paper demonstrate the dual nature of NSE, which can limit the effect of firms' use of internal resources while strengthening the use of external resources on firm performance. The finding explains the inconsistency results on the relationship between network status and firm performance in previous studies and provides an empirical basis for future studies on firm cooperation.

Conclusions in this paper have following practice implications for firms. Firstly, it suggests that the impacts of different $R \& D$ modes on financial performance and innovation performance are variable. Therefore, firms should choose R\&D modes in line with their performance objectives. Specifically, for example, for firms that wish good financial performance, they are supposed to adopt the other three R\&D modes instead of internal exploitation. Secondly, once a certain R\&D mode is determined, firms can strengthen the target effect by changing the network position. Thirdly, the dual nature of network structure efficiency requires firms to make dynamic strategic adjustments. Since network structure efficiency has a differential impact on the utilization of internal and external resources, firms are asked to adjust their network position according to performance goals to avoid the negative impact of network structure efficiency, instead of staying statical in a certain network structure.

Our study contains following limitations that open the door for future research.

Firstly, we use patent information to construct variables of R\&D modes. However, not all collaborations are captured by patent indicators. For example, the specific IP arrangements between the collaborative partners may result in only one applicant, which means that the intensity of external R\&D mode in the paper should be considered as a conservative estimate. Future studies should include more collaborative indicators to further assess and confirm the results. Secondly, future studies should increase control variables from more aspects, such as environmental uncertainty, competition and employee flow to pinpoint research findings.

\section{Acknowledgement}

We would like to thank the financial support from the National Natural Science Foundation of China 
(Grant No. 71802028, Principle investigator: Yan, Mengling) titled "The building mechanisms and performance impacts of cross-boundary organizational ambidexterity in growth-oriented high-tech companies".

\section{References}

[1] Boiko, Kseniia. "R\&D activity and firm performance: mapping the field." Management Review Quarterly (2021): 1-37.

[2] Piga, Claudio A., and Marco Vivarelli. "Internal and external R\&D: a sample selection approach." Oxford Bulletin of Economics and Statistics 66.4 (2004): 457482.

[3] Lokshin, Boris, René Belderbos, and Martin Carree. "The productivity effects of internal and external R\&D: Evidence from a dynamic panel data model." Oxford bulletin of Economics and Statistics 70.3 (2008): 399413.

[4] Narula, Rajneesh. "Choosing between internal and noninternal R\&D activities: some technological and economic factors." Technology Analysis \& Strategic Management 13.3 (2001): 365-387.

[5] Simonin, Bernard L. "Ambiguity and the process of knowledge transfer in strategic alliances." Strategic management journal 20.7 (1999): 595-623.

[6] Fritsch, Michael, and Grit Franke. "Innovation, regional knowledge spillovers and R\&D cooperation." Research policy 33.2 (2004): 245-255.

[7] Okamuro, Hiroyuki, Masatoshi Kato, and Yuji Honjo. "Determinants of R\&D cooperation in Japanese startups." Research policy 40.5 (2011): 728-738.

[8] d'Aspremont, Claude, and Alexis Jacquemin. "Cooperative and noncooperative R \& D in duopoly with spillovers." The American Economic Review 78.5 (1988): 1133-1137.

[9] Chesbrough, Henry, Wim Vanhaverbeke, and Joel West, eds. Open innovation: Researching a new paradigm. Oxford University Press on Demand, 2006.

[10] Enkel, Ellen, Oliver Gassmann, and Henry Chesbrough. "Open R\&D and open innovation: exploring the phenomenon." R\&d Management 39.4 (2009): 311-316.

[11] Hung, Kuang-Peng, and Christine Chou. "The impact of open innovation on firm performance: The moderating effects of internal R\&D and environmental turbulence." Technovation 33.10-11 (2013): 368-380.

[12] Russo, Angeloantonio, and Clodia Vurro. "Cross boundary ambidexterity: Balancing exploration and exploitation in the fuel cell industry." European Management Review 7.1 (2010): 30-45.

[13] Gupta, Anil K., Ken G. Smith, and Christina E. Shalley. "The interplay between exploration and exploitation." Academy of management journal 49.4 (2006): 693-706.

[14] Gilsing, Victor, et al. "Network embeddedness and the exploration of novel technologies: Technological distance, betweenness centrality and density." Research policy 37.10 (2008): 1717-1731.

[15] Burt, Ronald S. Structural holes. Harvard university press, 1992.
[16] Zaheer, Akbar, and Geoffrey G. Bell. "Benefiting from network position: firm capabilities, structural holes, and performance." Strategic management journal 26.9 (2005): 809-825.

[17] Faems, Dries, Bart Van Looy, and Koenraad Debackere. "Interorganizational collaboration and innovation: Toward a portfolio approach." Journal of product innovation management 22.3 (2005): 238-250.

[18] Lundvall, Bengt-Åke. "Explaining inter-firm cooperation and innovation-Limits of the transaction cost approach." (1990).

[19] Berchicci, Luca. "Towards an open R\&D system: Internal R\&D investment, external knowledge acquisition and innovative performance." Research policy 42.1 (2013): 117-127.

[20] Lavie, Dovev, and Stewart R. Miller. "Alliance portfolio internationalization and firm performance." Organization science 19.4 (2008): 623646.

[21] Jiang, Ruihua Joy, Qingjiu Tom Tao, and Michael D. Santoro. "Alliance portfolio diversity and firm performance." Strategic management journal 31.10 (2010): 1136-1144.

[22] Mavroudi, Eva, Effie Kesidou, and Krsto Pandza. "Shifting back and forth: How does the temporal cycling between exploratory and exploitative R\&D

[23] Rindfleisch, Aric, et al. "Cross-sectional versus longitudinal survey research: Concepts, findings, and guidelines." Journal of marketing research 45.3 (2008): 261-279.

[24] Tushman, Michael L., and Charles A. O'Reilly III. "Ambidextrous organizations: Managing evolutionary and revolutionary change." California management review 38.4 (1996): 8-29.

[25] March, James G. "Exploration and exploitation in organizational learning." Organization science 2.1 (1991): 71-87.

[26] Laursen, Keld, and Ammon Salter. "Open for innovation: the role of openness in explaining innovation performance among UK manufacturing firms." Strategic management journal 27.2 (2006): 131150.

[27] Linton, Jonathan D., and Steven T. Walsh. "Integrating innovation and learning curve theory: an enabler for moving nanotechnologies and other emerging process technologies into production." $R \& D$ Management 34.5 (2004): 517-526.

[28] Tsai, Kuen-Hung, and Jiann-Chyuan Wang. "External technology acquisition and firm performance: A longitudinal study." Journal of Business Venturing 23.1 (2008): 91-112.

[29] Fischer, Thomas, et al. "Exploitation or exploration in service business development? Insights from a dynamic capabilities perspective." Journal of Service Management (2010).

[30] Hamel, Gary. "Competition for competence and interpartner learning within international strategic alliances." Strategic management journal 12.S1 (1991): 83-103.

[31] Teece, David J. "The diffusion of an administrative innovation." Management science 26.5 (1980): 464-470. 
[32] Lampert, Curba Morris, and Minyoung Kim. "Going far to go further: Offshoring, exploration, and R\&D performance." Journal of business research 103 (2019): 376-386.

[33] Tether, Bruce S. "Who co-operates for innovation, and why: an empirical analysis." Research policy 31.6 (2002): 947-967.

[34] Mora-Valentin, Eva M., Angeles Montoro-Sanchez, and Luis A. Guerras-Martin. "Determining factors in the success of R\&D cooperative agreements between firms and research organizations." Research policy 33.1 (2004): 17-40.

[35] Powell, Walter W., Kenneth W. Koput, and Laurel Smith-Doerr. "Interorganizational collaboration and the locus of innovation: Networks of learning in biotechnology." Administrative science quarterly (1996): 116-145.

[36] Ibarra, Herminia. "Network centrality, power, and innovation involvement: Determinants of technical and administrative roles." Academy of Management journal 36.3 (1993): 471-501.

[37] Levinthal, Daniel A., and James G. March. "The myopia of learning." Strategic management journal 14.S2 (1993): 95-112.

[38] Andriopoulos, Constantine, and Marianne W. Lewis. "Exploitation-exploration tensions and organizational ambidexterity: Managing paradoxes of innovation." Organization science 20.4 (2009): 696-717.

[39] Lahiri, Nandini, and Sriram Narayanan. "Vertical integration, innovation, and alliance portfolio size: Implications for firm performance." Strategic Management Journal 34.9 (2013): 1042-1064.

[40] Ahuja, Gautam, Francisco Polidoro Jr, and Will Mitchell. "Structural homophily or social asymmetry? The formation of alliances by poorly embedded firms." Strategic management journal 30.9 (2009): 941958.

[41] Uzzi, Brian. "Social structure and competition in interfirm networks..." Administrative Science Quarterly 42.1 (1997): 37-69.

[42] Gentry, Richard J., and Wei Shen. "The relationship between accounting and market measures of firm financial performance: How strong is it?." Journal of managerial issues (2010): 514-530.

[43] Hagedoorn, John, and Myriam Cloodt. "Measuring innovative performance: is there an advantage in using multiple indicators?." Research policy 32.8 (2003): 1365-1379.

[44] Karamanos, Anastasios G. "Effects of a firm's and their partners' alliance ego-network structure on its innovation output in an era of ferment." $R \& D$ Management 46.S1 (2016): 261-276.

[45] Wang, Chunlei, et al. "Knowledge networks, collaboration networks, and exploratory innovation." Academy of Management Journal 57.2 (2014): 484-514.

[46] Becker-Blease, John R., et al. "Employees, firm size and profitability of US manufacturing industries." Investment Management and Financial Innovations (2010).
[47] Wilson, Robert W. "The effect of technological environment and product rivalry on R\&D effort and licensing of inventions." The Review of Economics and Statistics (1977): 171-178

[48] Begley, Thomas M. "Using founder status, age of firm, and company growth rate as the basis for distinguishing entrepreneurs from managers of smaller businesses." Journal of business venturing 10.3 (1995): 249-263.

[49] Gee, Robert E. "The Opportunity Criterion-A New Approach to the Evaluation of R\&D." Research Management 15.3 (1972): 64-71.

[50] Kuo, Chia - I., Chia - Hung Wu, and Bou - Wen Lin. "Gaining from scientific knowledge: the role of knowledge accumulation and knowledge combination." R\&D Management 49.2 (2019): 252-263.

[51] Cassiman, Bruno, and Reinhilde Veugelers. "In search of complementarity in innovation strategy: Internal $\mathrm{R} \& \mathrm{D}$ and external knowledge acquisition." Management science 52.1 (2006): 68-82.

[52] Ahuja, Gautam, and Curba Morris Lampert. "Entrepreneurship in the large corporation: A longitudinal study of how established firms create breakthrough inventions." Strategic management journal 22.6 - 7 (2001): 521-543.

[53] Moilanen, Mikko, Stein Østbye, and Kristin Woll. "NonR\&D SMEs: external knowledge, absorptive capacity and product innovation." Small Business Economics 43.2 (2014): 447-462.

[54] Wilden, Ralf, et al. "Dynamic capabilities and performance: strategy, structure and environment." Long range planning 46.1-2 (2013): 7296.

[55] Kauppila, Olli-Pekka. "Creating ambidexterity by integrating and balancing structurally separate interorganizational partnerships." Strategic organization 8.4 (2010): 283-312.

[56] Barney, Jay. "Firm resources and sustained competitive advantage." Journal of management 17.1 (1991): 99120.

[57] Parker, Geoffrey G., and Marshall W. Van Alstyne. "Two-sided network effects: A theory of information product design." Management science 51.10 (2005): 1494-1504.

[58] Cohen, Wesley M., and Daniel A. Levinthal. "Absorptive capacity: A new perspective on learning and innovation." Administrative science quarterly (1990): 128-152.

[59] Yu, Yue, Ling Yuan, and Jian Li. "Knowledge search modes and innovation performance: The moderating role of strategic R\&D orientation." Technology Analysis \& Strategic Management 31.6 (2019): 625-640.

[60] Hoang, H. A., and Frank T. Rothaermel. "Leveraging internal and external experience: exploration, exploitation, and R\&D project performance." Strategic management journal 31.7 (2010): 734-758.

[61] Lane, Peter J., and Michael Lubatkin. "Relative absorptive capacity and interorganizational learning." Strategic management journal 19.5 (1998): 461-477 